\title{
Finite Deformation and Viscoelasticity Modeling and Test
}

\author{
Tibi Beda $^{1,2}$, Yvon Chevalier ${ }^{3}$, Kokou-Esso Atcholi ${ }^{4}$, Essole Padayodi ${ }^{4}$, Jean-Claude Sagot ${ }^{4}$ \\ ${ }^{1}$ Industrial and Mechanical Engineering Department, Ecole Nationale Supérieure Polytechnique, Yaounde, Cameroon \\ ${ }^{2}$ Département de Physique, Faculté des Sciences, Université de Ngaoundéré, Ngaoundéré, Cameroon \\ ${ }^{3}$ Laboratoire d'Ingénierie des Structures Mécanique et des Matériaux, Saint Ouen, France \\ ${ }^{4}$ Laboratoire Systèmes \& Transport (SeT EA 3317), Université de Technologie de Belfort-Montbéliard, Belfort Cedex,France \\ E-mail: tbeda@yahoo.com,yvon.chevalier@supmeca.fr, \\ $\{$ kokou-esso.atcholi,essole.padayodi,jean-claude.sagot $\} @ u t b m . f r$ \\ Received January 19, 2011; revised July 10, 2011; accepted July 20, 2011
}

\begin{abstract}
A model is considered as a representation of compressive and incompressive elastomeric materials in nonlinear behavior. Applications are done on one hand by the characterisation of polyurethane 60 - 65 shore A (a compressive material), and on the other hand by the characterisation of polyurethane 95 shore A and fluorosilicone, both incompressive materials. The Rivlin energy expression is used for incompressive materials. Linear vibrations superposed on static large deformation, which is most often the real using state of elastomeric materials, are studied. Relative experimental and numerical results presented show good predictions.
\end{abstract}

Keywords: Elastomeric Materials, Nonlinear Behavior, Material Testing, Compressibility Modeling, BKZ Model, Mechanical Properties

\section{Introduction}

Elastomeric materials (Rubber, polyurethane, fluorosilicone) are widely used in industry over the past decades; it shows evidence of progress in this field of material researches. Rubberlike materials, compact or porous, have very complex mechanical behavior: for a small loading, this kind of material presents large strains (many percents); stress depends on strain velocity, incompressibility and temperature. Reason why, the thermomechanical behavior of these materials, take into account nonlinear viscoelastic effects: geometrical nonlinearity and nonlinear constitutive law.

The nonlinear behavior of materials can be described by a lot of models based on undeformed configuration (Lagrangien description) in which, behavior of hyperelastic materials needs relationship between Piola-Kirchhoff stress tensor $\mathbf{S}$ and Green-Lagrange strain tensor $\mathbf{E}$. In deformed configuration (Eulerian description) mechanical behavior of materials is described by relationship between the Cauchy stress tensor $\sigma$ [1] and the strain tensor of Almansi A. The first standpoint is useful in prediction and computational approach of mechanical systems whereas the second standpoint is used for experimental analysis of materials.
We tried to present mechanical behavior of rubber materials in the frame of non-linear viscoelasticity under small compressibility and large deformations. The final model is a combination of hyperelasticity and viscoelasticity. We pointed out two directions based on tests when using this kind of model: relaxation and vibration test under various loading.

\section{Modeling Nonlinear Elasticity}

A lot of models can be used to describe non-linear viscoelastic behavior of materials. The common model is a mathematical model based on multiple convolutions. The stress tensor of Piola-Kirchhoff $\mathbf{S}$ is related to strain Green-Lagrange tensor E by Volterra-Frechet series [2-5]. This is a very complex approach which requires special tests on materials to determine kernel of each rank. Lai and Findley [2] propose parabolic kernel (in time) for rank 1, 2 and 3. We take up a more pragmatic way to describe viscoelastic behavior of material $[6,7]$ based on linear approach. In Schapery model [7], nonlinearities are expressed in term of variable multiplying factors (stress, strain, times ...). The model presented is close to O'Down and Knauss [8]; and Valanis and Landel model [9] using single convolution to describe mem- 
ory effect of material while elasticity is expressed in term of hyperelasticity. The Piola-Kirchhoff stress tensor $\mathbf{S}(\mathbf{t})=\left(S_{i j}(t)\right)$ is related to Green-Lagrange strain tensor $\mathcal{E}(\mathbf{t})=\left(\mathcal{E}_{i j}(t)\right)$, see Beda and Chevalier works [10], by the following equations for positive values of time :

$$
\mathrm{S}_{\mathrm{ij}}(t)=\frac{\partial w}{\partial \mathcal{E}_{\mathrm{ij}}}(\mathcal{E}(\mathbf{t}))-\int_{0}^{t} \frac{\partial}{\partial \tau}\left\{R_{i j k l}[\mathcal{E}(\mathbf{t}), t-\tau]\right\} \mathcal{E}_{k l}(\tau) \mathrm{d} \tau
$$

where $\mathrm{w}$ is the strain energy density and $\mathbf{R}=\left(\mathrm{R}_{\mathrm{ijk} 1}[\mathcal{E}(\mathbf{t}), t]\right)$ is the fourth rank relaxation tensor (independent functions for isotropic materials). The constitutive relations (1) are consistent with previous model if the following compatibility relations between strain energy density and relaxation functions are satisfied [10].

$$
\frac{\partial w}{\partial \mathcal{E}_{\mathrm{ij}}}[\mathcal{E}(\mathbf{t})]=R_{i j k l}[\mathcal{E}(\mathbf{t}), 0] \mathcal{E}_{k l}(t)
$$

The nonlinear viscoelasticity described by relation (1) is a general formulation and can be widely applied. The model can be update by two classical viscoelastic tests: transient test and vibration test under large deformations.

\section{Transient Relaxation Test}

To take into account the compressibility of isotropic rubberlike materials the strain energy density is based on B.K.Z (Bernstein, Kearsley, Zapas) model:

$$
W=W_{D}^{*}\left(\Gamma_{1}, \Gamma_{2}\right)+Q\left(\Gamma_{1}, \Gamma_{2}\right) \mathrm{L}_{\mathrm{n}} \Gamma_{3}+G\left(\Gamma_{3}\right)
$$

where:

$$
\Gamma_{1}=I_{1} I_{3}^{-\frac{1}{3}}, \Gamma_{2}=I_{2} I_{3}^{-\frac{2}{3}}, \Gamma_{3}=I_{3}
$$

$I_{1}, I_{2}, I_{3}$ are the three invariants of the right Cauchy strain tensor $\mathbf{C}=\left(C_{i j}\right)=\mathbf{F}^{\mathbf{t}} \mathbf{F}$, where $\mathbf{F}$ is the deformation gradient operator, $\mathrm{L}_{\mathrm{n}}$ a parameter.

$$
\begin{aligned}
& I_{1}=\operatorname{tr}(\mathbf{C})=C_{i j} \delta_{i j} \\
& I_{2}=\frac{1}{2}\left\{[\operatorname{tr}(\mathbf{C})]^{2}-\operatorname{tr}\left(\mathbf{C}^{2}\right)\right\} \\
& I_{3}=\operatorname{det}(\mathbf{C})
\end{aligned}
$$

$W_{D}^{*}\left(\Gamma_{1}, \Gamma_{2}\right)$ allows us to bring back to incompressible material [11], $G\left(\Gamma_{3}\right)$ is the penalty function $\left(G(1)=\frac{\mathrm{d} G}{\mathrm{~d} \Gamma_{3}}(1)=0\right)$ and $Q\left(\Gamma_{1}, \Gamma_{2}\right)$ is a coupling factor between compressive and incompressible materials. When analyzing polyurethane materials, the following modeling (Rivlin hyperelasticity law) is held:

$$
W_{D}^{*}\left(\Gamma_{1}, \Gamma_{2}\right)=\sum_{i, j=0}^{M} \mathrm{~A}_{\mathrm{ij}}\left(\Gamma_{1}-z\right)^{i}\left(\Gamma_{2}-z\right)^{j}
$$

with $M \leq 3$ and $A_{i j}$ material characteristics related to the distortional response.

The penalty function depends on bulk modulus $K$ of material; it means that the relative variation of pressure is proportional to relative volume variation.

$$
G\left(\Gamma_{3}\right)=K\left[\sqrt{\Gamma_{3}}-1-\frac{L_{n} \Gamma_{3}}{2}\right]
$$

The coupling function $\mathrm{Q}$ is given in terms of series:

$$
Q\left(\Gamma_{1}, \Gamma_{2}\right)=\sum_{n=0}^{N} \mathrm{a}_{\mathrm{n}}\left(\frac{\Gamma_{1}}{\Gamma_{2}}-1\right)^{n+1}
$$

where coefficients $a_{n}$ are determined by tensile test and mathematical regression $[12,13], N \leq 2$.

Table 1 relates Rivlin constants for polyurethane given by using uniaxial tensile tests [14].

For compressible material (polyurethane 60 - 65 shore A) the coupling function is given by curves, Figure 1, with bulk modulus $K \cong 23 \mathrm{MPa}$.

Table 1. First part of energy deformation density of polyurethane. Result of Uniaxial tensile test under elongation $\lambda$ $(1 \leq \lambda \leq 1.2)$.

\begin{tabular}{cccccc}
\hline & \multicolumn{5}{c}{$W_{D}^{*}$ (relation 5) } \\
\cline { 2 - 6 } Material (in MPa) & $\mathrm{A}_{10}$ & $\mathrm{~A}_{01}$ & $\mathrm{~A}_{11}$ & $\mathrm{~A}_{20}$ & $\mathrm{~A}_{02}$ \\
\hline $\begin{array}{c}\text { Polyurethane 60 - 65 shore A } \\
\text { (compressive: } v=0.3)\end{array}$ & 0.216 & 0.226 & -0.227 & 0 & 0 \\
$\begin{array}{c}\text { Polyurethane 95 shore A } \\
\text { (incompressive) }\end{array}$ & 13 & -6.74 & 14 & 69.7 & -130 \\
\hline
\end{tabular}

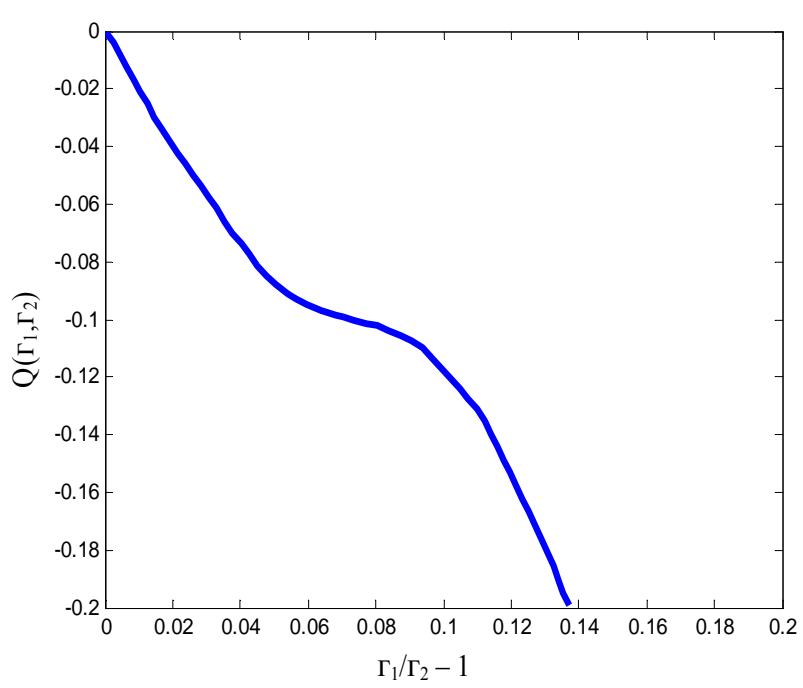

Figure 1. Coupling function $Q$ versus invariant of right Cauchy Green tensor. 
For incompressible materials (polyurethane 95 shore A) function $Q$ and $G$ can be neglected in relation (3).

Concerning the memory effect of material, we carried out tensile relaxation tests and retained for relaxation function usual Prony's series model in which parameters depend on Green-Lagrange tensor $\mathcal{E}(t)$. In the case of tensile test, the relaxation tensor $\mathbf{R}(\lambda, t)$ is given by the following expression:

$$
R(\lambda, t)=H(\lambda)\left[1+\sum_{i=1}^{3} r_{i}(\lambda) \exp \left(-\frac{t}{\tau_{i}(\lambda)}\right)\right]
$$

where $\lambda$ is the stretch.

Tensile relaxation tests are carried out under four different stretches $(\lambda=1.05, \lambda=1.10, \lambda=1.15, \lambda=1.20)$.

One remark that for the polyurethane 95 shore A, an incompressive material, the second order model describes quite well the material behavior prediction.

Figure 2 relates the evolution of magnitude factors $\left(r_{1}, r_{2}, r_{3}\right)$ and time constants $\left(\tau_{1}, \tau_{2}, \tau_{3}\right)$ versus stretch $\lambda$. It shows that the stretch $\lambda$ weakens stiffness of material ( $\mathrm{r}_{\mathrm{i}}$ decreases with increasing $\lambda$ ) and reinforces the elasticity ( $\tau$ increases with increasing $\lambda$ ).

Let us examine the consistency of the model and the compatibility, relations (2).

Table 2 shows that assessment of the compatibility, relation (2) is satisfactory (discrepancy $\cong 5 \%$ ). Finally we try a comparison between the actual Cauchy stress tensor $\sigma$ and the Cauchy stress tensor predicted by the model at two strain velocities.

Figure 3 shows that the model gives a better prediction at low strain velocity which is close to static behavior.
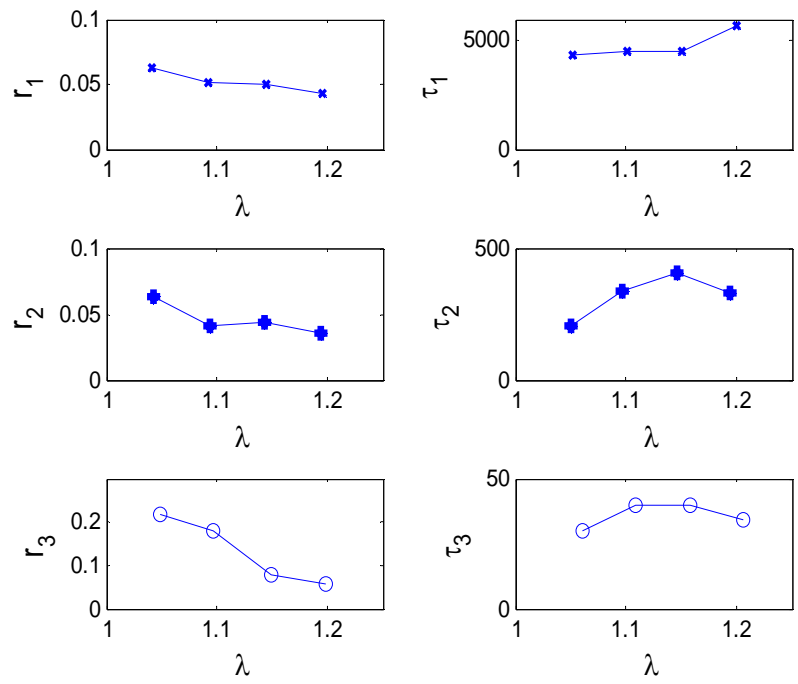

Figure 2. Variation of magnitude factor $\left(r_{i}\right)$ and time constant $\left(\tau_{i}\right),(i=1,2,3$ relation 8$)$, versus elongation $\lambda$ for polyurethane 95 shore $A$.
Table 2. Comparison between static and relaxation behavior of polyurethane 95 shore A. Validity of compatibility.

\begin{tabular}{ccccc}
\hline$\lambda_{0}$ & 1.05 & 1.10 & 1.15 & 1.20 \\
\hline $\begin{array}{c}\partial w / \partial \mathcal{E}\left(\mathcal{E}_{0}\right)[\mathrm{Mpa}] \\
(\text { quasi static tension) }\end{array}$ & 1.91 & 2.85 & 3.58 & 4.07 \\
$\mathrm{R}\left(\mathcal{E}_{0}\right), \mathcal{E}_{0}[\mathrm{Mpa}]$ & 1.80 & 2.94 & 3.62 & 3.70 \\
$\begin{array}{c}(\text { relaxation }) \\
\text { Validity } \\
\text { (in \%) }\end{array}$ & 6 & 3 & 1 & 9 \\
\hline
\end{tabular}

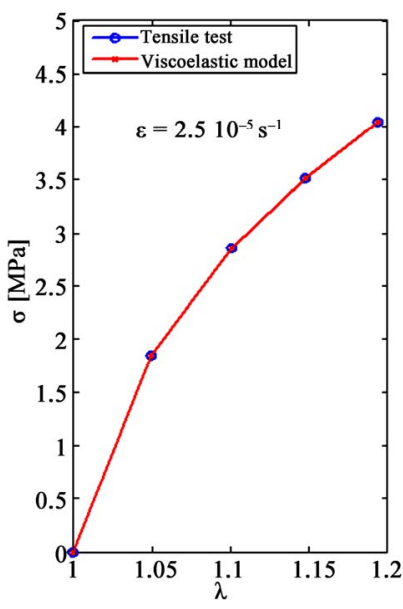

(a)

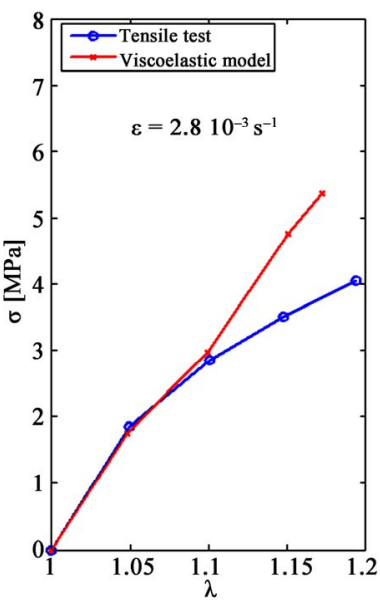

(b)
Figure 3. Comparison between model and test at various strain velocities.

\section{Vibrations Tests}

In industrial context, the great majority of rubber materials are working under static load (large strain $\mathcal{E}_{0}$ ) on where small vibrations $\varepsilon(t)$ are superposed.

See for example rubber connection in vibrating structures (rotating engine, car engine, etc. ...).

The total strain is then given by the following relations:

$$
\mathcal{E}_{i j}(t)=\mathcal{E}_{i j}^{0}+\varepsilon_{i j}(t)
$$

in which $\left|\varepsilon_{\mathrm{ij}}(t)\right| \square 1$.

Constitutive relations (1) are expanded till first order:

$$
\left\{\begin{array}{l}
\frac{\partial w}{\partial E_{i j}}(\mathcal{E})=\frac{\partial w}{\partial E_{i j}}\left(\mathcal{E}^{o}\right)+\frac{\partial^{2} w}{\partial E_{i j} \partial E_{k l}}\left(\mathcal{E}^{o}\right) \varepsilon_{k l}(t) \\
R_{i j k l}[\mathcal{E}(\tau), t-\tau]=R_{i j k l}\left[E_{0}, t-\tau\right]+\frac{\partial R_{i j k l}}{\partial E_{p q}}\left[\mathcal{E}_{0}, t-\tau\right] \varepsilon_{\mathrm{pq}}(\tau)
\end{array}\right.
$$

and the Piola-Kirchhoff stress tensor is a sum of two stress tensors $S^{0}(t)$ and $S^{1}(t)$ given by relations (10) and (11):

$$
S_{i j}^{0}(t)=\left\{R_{i j k l}\left(E_{0}\right)+\frac{\partial R_{i j k l}}{\partial E_{p q}} \cdot \varepsilon_{p q}\left(0^{+}\right)\right\} E_{k l}^{0}
$$




$$
S_{i j}^{1}(t)=R_{i j k l}\left[\mathcal{E}_{0}, 0\right] \varepsilon_{k l}(t)+\int_{0}^{t} \frac{\partial R_{i j k l}}{\partial \tau}\left[\mathcal{E}_{0}, t-\tau\right] \mathrm{d} \tau
$$

$\mathbf{S}^{0}(t)$ is static stress, constant for large value of time while $\mathbf{S}^{1}(t)$ relates linear viscoelastic behavior around large strain $\mathcal{E}_{0}$.

Experimental setups involving longitudinal vibration of beams [15-17] are presented in Figure 4.

Figure 5 shows experimental curves of Young modulus of fluorosilicone rubber material. Analytic formulas for constitutive equations of viscoelastic materials are provided to predict behavior of material under large range of frequencies and different stretches. To describe the behavior of realistic viscoelastic material, a fractional derivative model [18-20] is used. The complex Young modulus can be written in the following form:
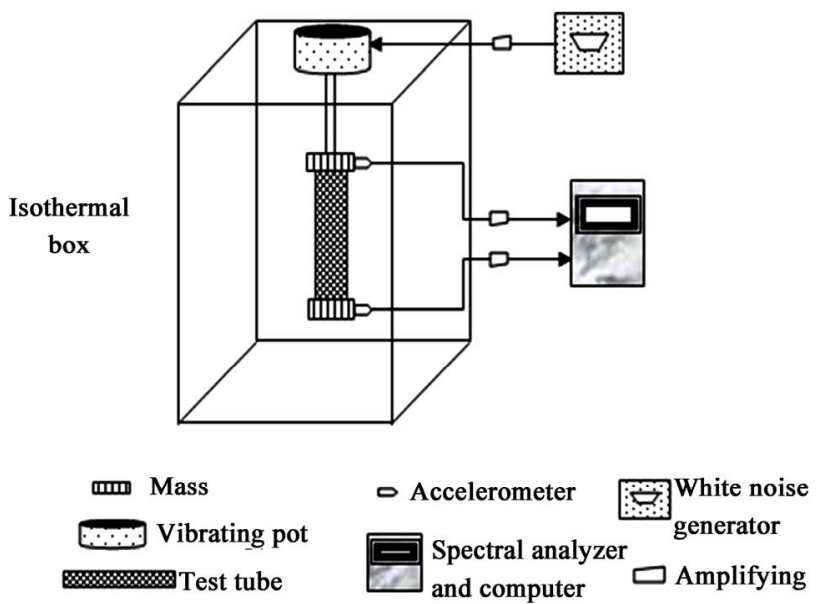

Figure 4. Experimental setups and data recording system used to evaluate complex Young modulus of rubber material.

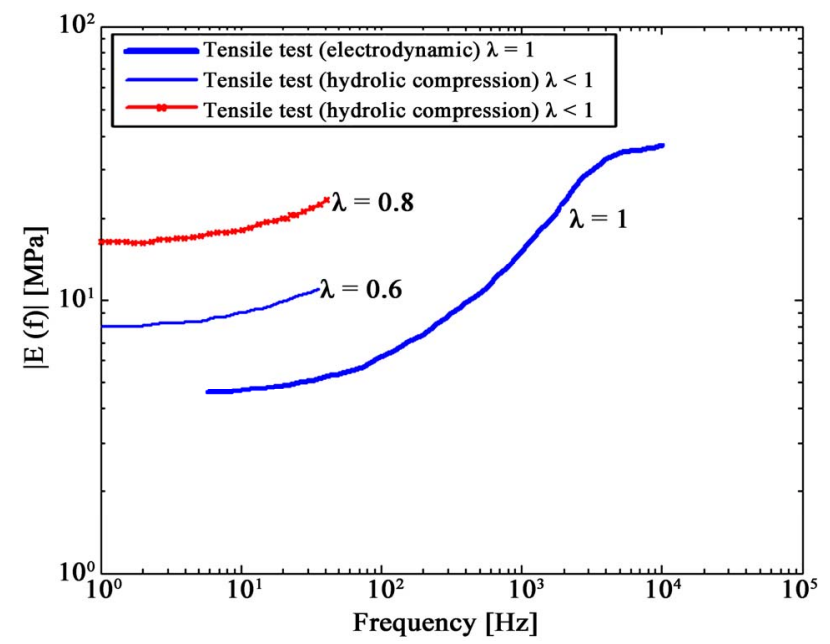

Figure 5. Amplitude of complex Young modulus of a fluorosilicone rubber material.

$$
E(f)=E_{0} \frac{\left[1+\left(\frac{i f}{f_{0}}\right)^{\alpha}\right]}{\left[1+\left(\frac{i f}{f_{1}}\right)^{\alpha}\right]}
$$

where $E_{0}, f_{0}, f_{1}$ and $\alpha$ are material parameters depending of the stretch $\lambda$. Numerical values of parameters are drawn out of tensile vibration test, Figure 6, and are exhibited in Table 3.

Results presented by forward-looking updating technique (tests and fractional derivative model) are in keeping with viscoelastic properties of materials [21]: the Young modulus gain increases with increasing loading while the damping factor decreases (the frequency of maximum damping increases with increasing loading).

\section{Concluding Remarks}

The whole interest of this nonlinear viscoelastic model is in engineering sciences: model can predict the effect of static loading of viscoelastic behavior of materials. Experimental complex Young modulus and complex Coulomb modulus can be obtained over a large frequencies range, to include the static and high frequencies moduli under various loading. Furthermore, the effect of loading is quantized in relaxation behavior of material.
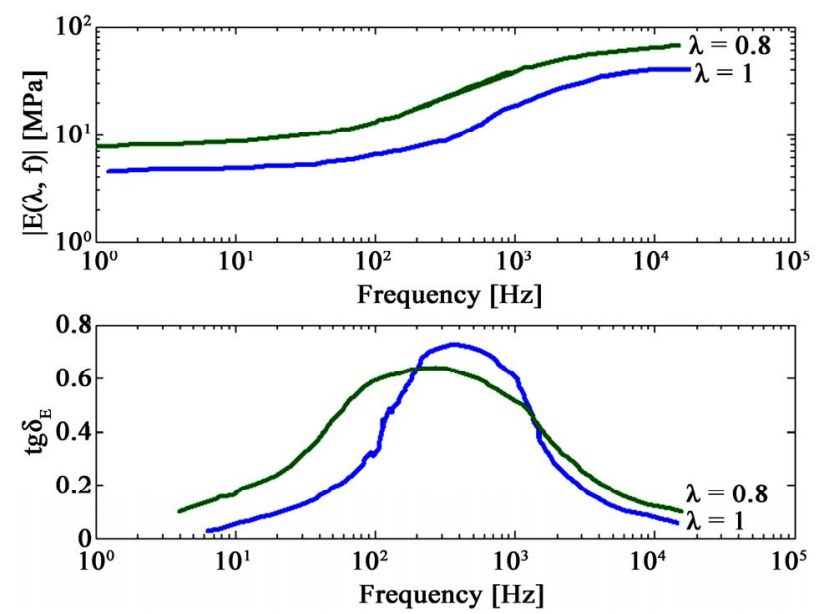

Figure 6. Young modulus of fluorosilicone rubber material versus frequency at various modeling. Curves are drawn from relation (12) and updated (Table 3).

Table 3. Numerical values of fractional derivative model of fluorosilicone rubber material under static load.

\begin{tabular}{ccccc}
\hline$\lambda$ Elongation & $E_{0}(\mathrm{MPa})$ & $\alpha$ & $f_{0}(\mathrm{~Hz})$ & $f_{1}(\mathrm{~Hz})$ \\
\hline 1 & 5.8 & 0.96 & 17.5 & 120 \\
0.8 & 8 & 0.75 & 5.6 & 127 \\
\hline
\end{tabular}


Some problems are open-ended. Is it allowed to use only lagrangian configuration? And vibrations tests? Finally is the model thermodynamically correct (by considering negative energetic constants)? These are among others perspectives to be looking at for sharpen the results awaited.

\section{References}

[1] J. Salencon, "Mécanique des Milieux Continus," Editions Ellispe, Paris, 1988.

[2] J. S. Lai and N. W. Findley, "Stress Relaxation of Nonlinear Viscoelastic Material under Uniaxial Strain," Transactions of the Society of Rheolog, Vol. 12, No. 2, 1968, pp. 259-280. doi:10.1122/1.549108

[3] F. J. Locket, "Nonlinear Viscoelastic Solids," Academic Press, San Diego, 1972.

[4] A. Molinari, "Sur la Relaxation Entre Fluage et Relaxation en Viscoélasticité non Linéaire," Comptes Rendus, Académie des Sciences, Tome 277, Série A, 1973, pp. 621-623.

[5] C. Huet, "Relations between Creep and Relaxation Function in Nonlinear Viscoelasticity with or without Aging," Journal of Rheology, Vol. 29, No. 3, 1985, pp. 245-257. doi:10.1122/1.549789

[6] B. D. Coleman and W. Noll, "Foundation of Linear Viscoelasticity," Reviews of Modern Physics, Vol. 33, No. 2, 1961, pp. 239-249. doi:10.1103/RevModPhys.33.239

[7] R. A. Schapery, "On the Characterization of Nonlinear Viscoelastic Materials," Polymer Engineering Science, Vol. 9, No. 4, 1969, pp. 295-310. doi:10.1002/pen.760090410

[8] N. P. O'Dowd and W. G. Knauss, "Time Dependent Large Principal Deformation of Polymers," Journal of the Mechanics and Physics of Solids, Vol. 43, No. 5, 1996, pp. 771-792.

[9] K. C. Valanis and R. F. Landel, "Large Axial Deformation Behavior of Filled Rubber," Transactions of the Society of Rheology, Vol. 11, 1967, pp. 213-256. doi:10.1122/1.549080

[10] T. Beda and Y. Chevalier, "Sur le Comportement Statique et Dynamique des Élastomères en Grandes Déformations," Mécanique Industrielle et Matériaux, Vol. 50, No. 5, 1997, pp. 228-231.
[11] R. W. Ogden, "Nonlinear Elastic Deformation," Ellis Horwood Edition, Robson, 1984.

[12] T. Beda, Y. Chevalier, H. Gacem and P. Mbarga, "Domain of Validity and Fit of Gent-Thomas and Flory-Erman Rubber Models to Data," Express Polymer Letters, Vol. 2, No. 9, 2008, pp. 615-622.

doi:10.3144/expresspolymlett.2008.74

[13] T. Beda, "Combining Approach in Stages with Least Squares for Fits of Data in Hyperelasticity," Comptes Rendus Mecanique, Académie des Sciences, Elsevier, Paris, Vol. 334, No. 10, 2006, pp. 628-633.

[14] H. Bechir, "Comportement Viscoélastique des Élastomères de Polyuréthane en Grandes DéformationsModélisation-Validation," Ph.D. Thesis in Mechanics, CNAM, Paris, 1996.

[15] M. Soula, T. Ving, Y. Chevalier, T. Beda and C. Esteoule, "Measurements of Isothermal Complex Moduli of Viscoelastic Materials over a Large Range of Frequencies," Journal of Sound and Vibration, Vol. 205, No. 2, 1997, pp. 167-184. doi:10.1006/jsvi.1997.0978

[16] M. Soula, T. Ving and Y. Chevalier, "Transient Responses of Polymers and Elastomers Deduced from Harmonic Responses," Journal of Sound and Vibration, Vol. 205, No. 2, 1997, pp. 185-203. doi:10.1006/jsvi.1997.0979

[17] Y. Chevalier, T. Beda and J. Merdrignac, "Détermination de Modules d'Young Complexes par Identification," Mécanique Matériaux, Electricité, GAMI, Vol. 32, No. 431, 1989, pp. 55-60.

[18] T. Beda and Y. Chevalier, "Identification of Viscoelastic Fractional Complex Modulus," American Institute of Aeronautics and Astronautics Journal, AIAA, Vol. 42, No. 7, 2004, pp. 1450-1456.

[19] Y. Chevalier and T. Beda, "Fractional Derivative in Materials and Structures Vibratory Behaviour: Identification Methods," Journal Européen des Systèmes Automatisés, Hermès Lavoisier, Vol. 42, No. 6-8, 2008, pp. 863-877.

[20] M. Soula and Y. Chevalier, "La Dérivée Fractionnaire en Rhéologie des Polymères-Application aux Comportements ÉLastiques et Viscoélastiques Linéaires et non Linéaires des Élastomères," ESAIM Proceeding, Vol. 5, 1998, pp. 193-204. doi:10.1051/proc:1998007

[21] A. D. Nashif, D. I. J. Jones and J. P. Henderson, "Vibration Damping," Wiley, New York, 1984. 